\title{
Comparative Study of Urinary Minerals and Their Effect on Stone Formation in Two Groups of Cystic Fibrosis (CF) and Healthy Children
}

\author{
Alireza Niknahad ${ }^{1}$, Lobat Shahkar $^{2,{ }^{*}}$, Farshid Kompani ${ }^{2}$, Maryam Montazeri ${ }^{1}$ and Ali Ahani Azar ${ }^{3}$ \\ ${ }^{1}$ Golestan University of Medical Sciences, Gorgan, Iran \\ ${ }^{2}$ Gorgan University of Medical Sciences, Taleghani Hospital, Gorgan, Iran \\ ${ }^{3}$ Gorgan University of Medical Sciences, Gorgan, Iran \\ "Corresponding author: Pediatric Pulmonologist, Assistant Professor of Gorgan University of Medical Science,Taleghani Hospital, Gorgan, Iran. Email: \\ lobatshahkar@yahoo.com
}

Received 2020 May 23; Accepted 2020 June 27.

\begin{abstract}
Background: Cystic Fibrosis (CF) is a systemic autosomal disorder and the most important chronic lung disease in children. Oxalate is the end product of vitamin C metabolism, which increases the risk of kidney stones, urinary bladder stones, and calcium deposits in CF patients.

Objectives: Considering the increased mineral excretion and the rate of stone formation in the urinary tract, examining the excretion of minerals will greatly help resolve clinical problems.

Methods: This descriptive-analytical study was performed on CF and healthy children in Gorgan in 2018 - 19. In this study, 40 CF children and 40 healthy children were randomly selected. After obtaining informed consent from the parents of the children, a random urine sample was collected to evaluate urine minerals. Children with abnormal urinary mineral excretion underwent ultrasonography. The data were analyzed by SPSS 18 using descriptive indices (mean \pm SD, frequency, and percentage) and statistical tests (independent $t$-test, chi-square test, and nonparametric tests).

Results: Out of $80 \mathrm{CF}$ and healthy children, 34 were girls, and the rest was boys. The mean age of the patients was $4.34 \pm 3.38$. The age difference was not significant between the groups $(\mathrm{P}>0.05)$. The mean urinary levels of phosphorus, uric acid, magnesium, and citrate were $0.87 \pm 1.01,1.16 \pm 0.68,0.23 \pm 0.18,2.37 \pm 3.13 \mathrm{mg} / \mathrm{mg}$ of creatinine. In the pediatric patient group, respectively (P $<0.001)$. The mean urinary calcium level in CF patients was $0.28 \pm 0.39$, which was lower than that in the healthy group. The mean urinary oxalate level was $0.13 \pm 0.20$ in CF patients, which was higher than that in the healthy group $(\mathrm{P}>0.05)$. Hyperoxaluria, hyperuricosuria, hypomagnesiuria, and hypocitraturia occurred in 35, 30, 62, and 7.5\% of the CF patients, respectively. Among the urinary minerals studied, hyperoxaluria was found to be a major determinant of stone formation risk in CF. No correlation was observed between the formation of stones and the rate of excretion of minerals $(\mathrm{P}>0.05)$.

Conclusions: In summary, CF patients are at an increased risk of developing citrate and calcium stones compared to the healthy group, which is associated with hyperuricosuria, hypocitraturia, and hyperoxaluria.
\end{abstract}

Keywords: Cystic Fibrosis, Urinary Minerals, Kidney Stones

\section{Background}

Cystic Fibrosis (CF) is a multi-systemic autosomal disorder in children and adolescents, often manifested by obstruction and infection of the respiratory tract, indigestion, and other adverse events. It is known to be the most common autosomal recessive and life-restricting disorder among white people (1-3). Epithelial dysfunction is the most common complication of this disease and the main cause of all patient problems. Cystic fibrosis is the most important cause of chronic pulmonary disease in children (1) and the most common cause of exocrine pancreatic insufficiency in early years of life, as well. It is also a com- mon cause of salt loss, nasal polyps, sinusitis, pertussis, rectum prolepsis, pancreatitis, and insulin-related hyperglycemia. Cystic fibrosis may manifest as growth failure and rarely as the cause of cirrhosis and other forms of liver disorders, male infertility, and increased chloride concentrations in sweat. Therefore, this disease is considered in the differential diagnosis of many pediatric diseases $(1,2)$. It is also possible in the disorders of respiratory and gastrointestinal tracts, caused by the concentrated secretion of these two systems due to chloride secretion abnormality (4). As a result of disorders in chloride, water, and electrolyte transmission, the secretions of the respiratory tract in these patients become concentrated and sticky, which, 
in turn, provide an environment desirable for the colonization of opportunistic pathogens, especially Pseudomonas aeruginosa. In fact, the most common cause of death in these patients is a chronic pulmonary infection by Pseudomonas aeruginosa (3).

Cystic fibrosis is inherited via recessive autosomal patterns. The corresponding gene is located at a single locus on the long arm of chromosome number 7 and is composed of 27 exons. This gene encodes a protein with 1,480 amino acids, called Cystic Fibrosis Transmembrane Regulator (CFTR). It is known that CFTR primarily affects the epithelial cells of airway tracts, gastrointestinal tracts (including the pancreas and gallbladder tracts), sweat glands, and genitourinary system $(1,2)$. Although CFTR mainly acts as a chloride channel, it has several regulatory roles, some of which include the inhibition of sodium transport through the epithelial cell sodium channels, regulation of ATP channels, regulation of intracellular vesicle transport, and inhibition of calcium-dependent chloride channels function.

The diagnosis of CF is usually made using clinical symptoms and high sweat chloride concentrations $(5,6)$. In the United States, the incidence of CF in the white population is one in every 3,500 live births, and its incidence in the black population is one in every 17,000 live births. Its global incidence varies from one in every 377 births in the UK to one in every 90,000 births in the Asian race of Hawaii. Cystic fibrosis is very common in Central and Northern Europe, as well as in people who had migrated from these areas. The DF508 mutation has a prevalence of $70 \%$ in the European white population, but its mutation is found between 13 and 44\% in Arabian, Indian, Iranian, and Turkish populations (3). Excessive levels of calcium, oxalate, and uric acid in urine can increase the risk of calcium stone in the urinary tract (7). Oxalate is the final product of Vitamin C metabolism, which increases the risk of kidney stones, urinary tract stones, bladder stones, and calcium deposition in the kidney among CF patients (8). In these patients, calcium oxalate kidney stones have been observed in several cases. In a study of 43 patients with CF without symptoms of urinary stone disease, urinary oxalate mean levels were increased in the whole patient sample, and the excretion of urinary calcium was decreased (9). In other studies, however, urinary calcium, oxalate, and uric acid levels were increased (10). The CF patients may exhibit very diverse phenotypes depending on the type of mutation so that more than 1000 mutations have been attributed to the CFTR gene so far. It is also due to the abnormal excretion of various minerals (oxalate, uric acid,calcium , and citrate) in these patients, which increases the rate of stone formation in the urinary tract (1).

\section{Objectives}

The evaluation of the amount of excreted minerals will greatly help in resolving clinical problems, and there is a need for studies on phenotypes specific to this region and specifically for Iranian children.

\section{Methods}

A descriptive-analytical, case-control study was performed on children with CF referring to Taleghani Pediatric Pulmonology Clinic of Gorgan Educational/Research Center, whose CF had been confirmed by the specialists of pediatric pulmonology. The study enrolled 54 children in the case group and 54 children in the control group. The case group included healthy children without CF, and no disease was found to interfere with their urinary minerals. After obtaining informed consent from the parents of healthy children and the parents of CF children selected based on the inclusion and exclusion criteria, random urine sample containers were provided with special preservatives to the patients referring to the CF Clinic of Taleghani Hospital in Gorgan. Random urine samples were collected and delivered to the laboratory. We trained the parents 24 hours before sample collection to avoid vitamin C supplements (due to interference with citrate), fruit juice, and any medication that could interfere with our test results (e.g., antibiotics). The sample collection would be postponed until the discontinuation of the drug. In the laboratory, the samples were examined with oxalate and citrate-specific kits produced by Behmedico and Parsazmoon and a Chem Well auto analyzer apparatus made in the US in 2014. Urine samples were randomly collected for the control group consisting of healthy children after the children and their parents were asked about the disease to ensure that they were healthy and without any disease. Their urine samples were collected, and urinary minerals were evaluated. Thereafter, all children with CF whose urine sample analysis was abnormal were sonicated for urinary stones. The data were analyzed by SPSS 18 using descriptive indices (frequency and percentage) and statistical tests (independent $t$-test and chi-square test).

\section{Results}

This study included 40 children with CF confirmed by pediatric pulmonology specialists and 40 healthy children regarding $\mathrm{CF}$.

The frequency distribution of sex was examined in this study, and the results showed that out of 80 children (CF and healthy), 34 (42.5\%) individuals were female, and 46 
(57.5\%) were male. There was no significant difference in the gender distribution between the two groups $(\mathrm{P}>0.05)$.

The mean age of CF patients was studied in terms of month and year. The mean age of the patients was $3.38 \pm$ 4.34. The lowest infant age was 11 months, and the highest age was for two children with CF aged 11 years. Healthy children had a higher mean age than the patients (5.01 \pm 1.09$)$, and the age range of the majority of the healthy children was between 4 and 6 years. The age difference between the case and control groups was not significant $(\mathrm{P}>0.05)$.

The mean urinary calcium level was $0.39 \pm 0.28$ $\mathrm{mg} / \mathrm{mg}$ creatinine in the patient group and $0.58 \pm 2.82$ $\mathrm{mg} / \mathrm{mg}$ creatinine in the healthy group. According to the Kolmogorov-Smirnov test, this index did not show a normal distribution $(\mathrm{P}<0.001)$. The Mann-Whitney test was used to compare the mean values between the two groups, which did not show any significant difference $(P=0.817)$ although urinary calcium excretion was lower in patients than in healthy children.

The mean urinary oxalate levels in the randomly collected urine samples of CF and healthy children were 0.13 \pm 0.20 and $0.09 \pm 0.09 \mathrm{mg} / \mathrm{mg}$ creatinine, respectively. Although urinary oxalate was higher in CF children than in healthy children, this difference was not considered significant by the Mann-Whitney test $(\mathrm{P}=0.079)$.

The mean urinary phosphorus levels in the randomly collected urine samples of healthy children and CF children were $0.37 \pm 0.22$ and $0.87 \pm 1.01 \mathrm{mg} / \mathrm{mg}$ creatinine, respectively. The difference was significant in the MannWhitney test $(\mathrm{P}=0.002)$.

The mean total urinary uric acid levels in 80 children (healthy and CF) was $0.78 \pm 0.64 \mathrm{mg} / \mathrm{mg}$ creatinine. The mean urinary uric acid in the randomly collected urine samples of CF children and healthy children was as follows. The comparison of mean values using the MannWhitney test showed a significant difference between the two groups $(\mathrm{P}=0.001)$. The group of healthy children had lower uric acid excretion than the patient group (Table 1).

\begin{tabular}{lcccc}
\hline Table 1. Mean Uric Acid Levels in Cystic Fibrosis and Healthy Children \\
\hline $\begin{array}{l}\text { Uric Acid } \\
\text { Excretion }\end{array}$ & Mean \pm SD & Minimum & Maximum & PValue $^{\mathrm{a}}$ \\
\hline CF & $1.16 \pm 0.68$ & 0.12 & 4.07 & \\
\hline Normal & $0.39 \pm 0.25$ & 0.04 & 1.27 & 0.001 \\
\hline Total & $0.78 \pm 0.64$ & 0.04 & 4.07 & \\
\hline
\end{tabular}

${ }^{\mathrm{a}}$ Mann-Whitney test

The mean urinary magnesium level was $0.23 \pm 0.18$ $\mathrm{mg} / \mathrm{mg}$ creatinine in CF children and $0.10 \pm 0.05 \mathrm{mg} / \mathrm{mg}$ creatinine in healthy children. The total urinary magnesium level in children was $0.15 \pm 0.16 \mathrm{mg} / \mathrm{mg}$ creatinine.
Regarding the normality of data using the KolmogorovSmirnov test, the Mann-Whitney test showed a significant difference in the mean values between the two groups ( $\mathrm{P}=$ 0.001).

The urinary citrate level measured in the randomly collected urine samples of CF patients was $3.37 \pm 2.13 \mathrm{mg} / \mathrm{mg}$ creatinine, and the mean level in 80 children was $1.40 \pm$ $2.40 \mathrm{mg} / \mathrm{mg}$ creatinine. Given the non-normal distribution of data $(\mathrm{P}<0.28)$, the Mann-Whitney test was used to compare the mean urinary citrate level, which showed a significant difference in the urinary citrate level between healthy and CF children. In other words, children with CF had more citrate excretion than the healthy group $(\mathrm{P}=0.001)$ (Table 2).

\begin{tabular}{lcccc}
\hline \multicolumn{5}{l}{ Table 2. Mean Urinary Citrate Level in Healthy and Cystic Fibrosis Children } \\
\hline $\begin{array}{l}\text { Citrate } \\
\text { Excretion }\end{array}$ & Mean \pm SD & Minimum & Maximum & PValue $^{\mathbf{a}}$ \\
\hline CF & $2.37 \pm 3.13$ & 0.08 & 14.18 & \\
Normal & $0.49 \pm 0.26$ & 0.04 & 1.12 & 0.001 \\
Total & $1.43 \pm 2.40$ & 0.04 & 14.18 & \\
\hline
\end{tabular}

${ }^{\mathrm{a}}$ Mann-Whitney test

The evaluation of the levels of inorganic metabolites and its comparison with normal values in patients with $\mathrm{CF}$ showed that hypocitaturia, and hypomagnesuria occurred in 7.5 , and $62 \%$ of the patients, respectively. Also, hyperuricosuria and hyperoxaluria were seen in 30 and $35 \%$ of the patients, respectively (Table 3).

The ultrasound examination of $40 \mathrm{CF}$ patients showed only one patient with kidney stones, and the remaining patients had no stones, and no association was observed between stone formation and mineral excretion $(\mathrm{P}>0.05)$.

\section{Discussion}

Cystic fibrosis is an autosomal recessive genetic disease resulting from a mutation in the CFTR gene that encodes the chlorine ion transporter channel protein. Cystic fibrosis is characterized by pancreatic insufficiency, intestinal malabsorption, growth disorders, and pulmonary diseases (11). Cystic fibrosis is lower among African, American, and Asian people than in Northern Europeans. The frequency of this mutation has been reported in different regions of Iran between 16 and 23\% (12). The urinary disorder is rare in children with $\mathrm{CF}$, and its prevalence in asymptomatic primary school children is $1 \%$ annually (13). Metabolic and genital disorders are the predisposing factors for urolithiasis (14).

Well-known metabolic risk factors for calcium stone formation and urinary calcium excretion include hyper- 


\begin{tabular}{|c|c|c|c|}
\hline Age, $y$ & Levels, mg/mg & Number & No. $(\%)$ \\
\hline Hyperuricosuria & & & $12(30)$ \\
\hline$<1$ & $>2.2$ & 1 & \\
\hline $1-3$ & $>1.9$ & 2 & \\
\hline $3-5$ & $>1.5$ & 0 & \\
\hline $5-10$ & $>0.9$ & 9 & \\
\hline Hyperoxaluria & & & $14(35)$ \\
\hline$<6 \mathrm{mo}$ & $>0.29$ & 0 & \\
\hline $6 \mathrm{mo}-2 \mathrm{y}$ & $>0.2$ & 3 & \\
\hline $2-5$ & $>0.11$ & 3 & \\
\hline $6-12$ & $>0.63$ & 8 & \\
\hline Hypocitraturia & & & $3(7.5)$ \\
\hline $0-5$ & $<0.42$ & 3 & \\
\hline$>5$ & $<0.25 \mathrm{mg} / \mathrm{mg}$ & 0 & \\
\hline Hypomagnasuria & & & $25(62)$ \\
\hline $0-1$ & $<0.48$ & 8 & \\
\hline $1-2$ & $<0.37$ & 3 & \\
\hline $2-3$ & $<0.34$ & 3 & \\
\hline $3-5$ & $<0.29$ & 3 & \\
\hline $5-7$ & $<0.21$ & 5 & \\
\hline $7-10$ & $<0.18$ & 6 & \\
\hline
\end{tabular}

calciuria, hyperoxaluria, and increased uric acid excretion through urine. In addition, a decrease in citrate excretion is another risk factor $(15,16)$. Major causes of nephrocalcinosis and nephrolithiasis are idiopathic factors, but these conditions occur sometimes due to a lack of specific enzymes, familial issues, and diseases such as CF (17).

It has been traditionally accepted that the kidneys are not affected by $\mathrm{CF}$, and so far, no significant changes in renal function have been observed in patients with CF. However, the CFTR protein is expressed in the renal epithelium and is found in proximal tubules, henella loop, distal tubules, and urinary collecting ducts (18). Although urolithiasis is commonly seen in CF patients over 20 years of age, it is not common in children. Despite a widespread agreement on the association between kidney stones and $\mathrm{CF}$, there are still some doubts about the mechanism of this association (19). Therefore, this study was designed to compare urinary minerals (calcium, oxalate, citrate, phosphorus, magnesium, and uric acid) and their effects on stone formation in two groups of CF children and healthy children.

In this study, the mean age of the patients was $3.34 \pm$ 3.38 years, which was lower in CF children than in the con- trol group, but this difference was not significant $(\mathrm{P}>0.05)$ $(3,20)$. Also, about $60 \%$ of the patients were male. The mean age of the patients in Qarachi and Rafi'i studies was reported as $62.05 \pm 31.11$ months and $71.38 \pm 61.85$ months, respectively, and approximately $60 \%-70 \%$ of the patients were male (21-23), which are consistent with the present study. However, in Ashtiani's study on 49 CF patients with a mean age close to the age of patients in our study, the gender of the majority of the patients was reported as female (24). In our study, approximately $2.5 \%$ of the patients had evidence of stones, which is close to the prevalence of urolithiasis $(3 \%-6 \%)$ reported in previous studies $(25,26)$.

In the current study, the minerals levels in the two groups of CF patients and healthy children were compared. The mean urinary levels of phosphorus, uric acid, magnesium, and citrate were $0.87 \pm 1.01,1.16 \pm 0.68,0.18$ \pm 0.23 , and $2.37 \pm 3.13 \mathrm{mg} / \mathrm{mg}$ creatinine in the pediatric patient group, respectively. The results also showed a significant difference between the two groups in the level of mineral salts, with the excretion of the above minerals in $\mathrm{CF}$ children being significantly higher than in healthy children $(\mathrm{P}<0.001)$. The mean urinary calcium level in patients with CF was $0.28 \pm 0.39 \mathrm{mg} / \mathrm{mg}$ creatinine, which was lower than the mean urinary calcium level in the healthy group. The mean urinary oxalate level was $0.13 \pm$ $0.20 \mathrm{mg} / \mathrm{mg}$ creatinine in CF patients, which was higher than the mean urinary oxalate level in the healthy group. Nonetheless, no significant difference was observed between the two groups. In spite of this, the comparison of urinary mineral excretion of CF patients with the normal values of general population revealed that nearly one-third (35\%) of the patients had hyperoxaluria. This was similar to urinary oxalate excretion reported by other researchers (35\% vs. $40 \%$ - $65 \%)(19,27)$.

Hyperoxaluria has been identified as a major risk factor for stone formation in CF patients. Hyperoxaluria is often due to intestinal absorption and is associated with malabsorption and steatosis (28). Low calcium in the diet of patients is the most common cause of increased intestinal absorption of dietary oxalate (29). Regular antibiotics against pulmonary infections may result in the reduction or elimination of oxalate-destroying bacteria in the intestine, especially anaerobic bacterium Oxalobacter (30). Based on the above findings and considering that there was no significant difference in the mean oxalate level between the healthy and patient groups in this study, this may be due to the patient's diet or laboratory techniques.

In the present study, hypocitraturia was observed in nearly $8 \%$ of children with CF, which was lower than the rate in other studies $(8,19,28,31)$. In some studies, low citrate secretion has been reported in the urine of CF patients, and this low excretion appeared to be associated with hy- 
pokalemia and acidosis (28). Evidence has shown that decreased potassium and its increased tubular uptake into renal cells may lead to decreased citrate excretion (19).

In this study, normal urinary calcium excretion was observed in $77 \%$ of the patients. Other studies have also reported low urinary calcium excretion, with only $12 \%-20 \%$ of the patients having hypercalciuria $(30,31)$. Bohles and Michalk found that urinary creatinine excretion was lower in CF patients than in controls (31). In the present study, despite a significant difference in the mean urinary calcium level between the healthy and patient groups, the difference in calcium excretion levels between the two groups was not significant. In a study of 34 patients with CF, Benture et al. also found that nearly 30 patients had normal urinary calcium excretion, and only four cases of hypercalciuria were observed, which could have been due to secondary causes such as glucocorticoid administration or inactivity. Moreover, while normal urinary calcium does not promote stone formation, other factors such as increased urinary oxalate excretion and renal phosphorus loss have been suggested as contributing factors to calcium stone formation in CF children (26). The hyperuricosuria rate observed in the present study was similar to the rates in other studies (30\% vs. $25 \%$ - 55\%) (21). High-protein diets and purine-rich pancreatic enzyme supplements may be risk factors for uric acid excretion in CF patients.

In summary, $\mathrm{CF}$ patients are at an increased risk of developing citrate and calcium stones compared to the healthy group, which is associated with hyperuricosuria, hypocitraturia, and hyperoxaluria.

\section{Acknowledgments}

We would like to thank the Department of Pediatrics of Golestan University of Medical Sciences for valuable assistance and all people who contributed to this study.

\section{Footnotes}

Authors' Contribution: Study concept and design: Dr. Farshid Kompani; acquisition of data: Dr. Alireza Niknahad; drafting of the manuscript: Dr. Maryam Montazeri; critical revision of the manuscript for important intellectual content: Dr. Lobat Shahkar; statistical analysis: Dr. Ali AhaniAzar; administrative, technical, and material support: Dr. Farshid Kompani; study supervision: Dr. Lobat Shahkar

Conflict of Interests: There are no conflicts of interest.

Ethical Approval: Ir.goums.1398.21

Funding/Support: This study was supported in part by a grant from Golestan University of Medical Sciences and the Pediatric Research Center of Taleghani Hospital.

\section{References}

1. Turner MA, Goldwater D, David TJ. Oxalate and calcium excretion in cystic fibrosis. Archives of disease in childhood. 2000;83(3):244-7.

2. Akhavan Niaki H, Esmaeili Dooki MR, Ghabeli Juibary A. Common CFTR gene mutation in cystic fibrosis patients in Mazandaran province, Iran. J Gorgan Uni Med Sci. 2008;10:38-44.

3. Akhavan Niaki H, Tabaripour R, Douki E, Reza M, Azizi M, Tavakoli Bazzaz J, et al. Poly T polymorphism consideration in normal individuals and cystic fibrosis patients in Mazandaran province, Iran. Tehran University Medical Journal TUMS Publications. 2010;68(1):19-23.

4. Speert DP, Henry D, Vandamme P, Corey M, Mahenthiralingam E. Epidemiology of Burkholderia cepacia complex in patients with cystic fibrosis, Canada. Emerging infectious diseases. 2002;8(2):181.

5. Fallahi G, Najafi M, Farhmand F, Bazvand F, Ahmadi M, Ahmadi F, et al. The clinical and laboratory manifestations of Iranian patients with cystic fibrosis. The Turkish journal of pediatrics. 2010;52(2):132.

6. Sly PD, Gangell CL, Chen L, Ware RS, Ranganathan S, Mott LS, et al. Risk factors for bronchiectasis in children with cystic fibrosis. New England Journal of Medicine. 2013;368(21):1963-70.

7. Khalilzadeh S, Hassanzad M, Boloursaz M, Tashayoie Nejad S, Baghaie $\mathrm{N}$, Fazlalizadeh $\mathrm{H}$, et al. Survey of serum fat-soluble vitamins, zinc, copper and selenium levels in patients with cystic fibrosis. Medical Science Journal of Islamic Azad Univesity-Tehran Medical Branch. 2014;24(1):29-32.

8. Kianifar H, Talebi S, Khazaei M, Talebi S, Alamdaran A, Hiradfar S. Predisposing factors for nephrolithiasis and nephrocalcinosis in cystic fibrosis. Iranian journal of pediatrics. 2011;21(1):65.

9. Dequin PF, Faurisson F, Lemarie E, Delatour F, Marchand S, Valat C, et al. Urinary excretion reflects lung deposition of aminoglycoside aerosols in cystic fibrosis. European Respiratory Journal. 2001;18(2):31622.

10. Borowitz D, Parad RB, Sharp JK, Sabadosa KA, Robinson KA, Rock MJ, et al. Cystic Fibrosis Foundation practice guidelines for the management of infants with cystic fibrosis transmembrane conductance regulator-related metabolic syndrome during the first two years of life and beyond. The Journal of pediatrics. 2009;155(6):S106-16.

11. Bridges N, Geddes' Cystic Fibrosis. Growth and puberty. Hodson. 2015:349.

12. Farjadian S, Moghtaderi M, Kashef S, Alyasin S, Najib K, Saki F. Clinical and genetic features in patients with cystic fibrosis in southwestern iran. Iranian journal of pediatrics. 2013;23(2):212.

13. Naseri M, Varasteh A, Alamdaran SA. Metabolic factors associated with urinary calculi in children. Iranian Journal of Kidney Diseases. 2010;4(1):32-8.

14. Green $\mathrm{H}$, Jones AM. The microbiome and emerging pathogens in cystic fibrosis and non-cystic fibrosis bronchiectasis. Seminars in respiratory and critical care medicine. Thieme Medical Publishers; 2015. p. 225-35.

15. Rizvi SAH, Naqvi SAA, Hussain Z, Hashmi A, Hussain M, Zafar MN, et al. Pediatric urolithiasis: developing nation perspectives. The Journal of urology. 2002;168(4 Part 1):1522-5.

16. Hussein NS, Gohar MR. Pneumatic ureterolithotripsy in paediatric and adolescent patients: a ten-year experience at the Hospital Universiti Sains Malaysia. Singapore medical journal. 2011;52(1):42-6.

17. Türk C, Knoll T, Petrik A, Sarica K, Straub M, Seitz C. Guidelines on urolithiasis. European association of urology. 2011.

18. Reichman G, De Boe V, Braeckman J, Michielsen D. Urinary incontinence in patients with cystic fibrosis. Scandinavian journal of urology. 2016;50(2):128-31. 
19. Terribile M, Capuano M, Cangiano G, Carnovale V, Ferrara P, Petrarulo $\mathrm{M}$, et al. Factors increasing the risk for stone formation in adult patients with cystic fibrosis. Nephrology Dialysis Transplantation. 2006;21(7):1870-5.

20. Perez-Brayfield MR, Caplan D, Gatti JM, Smith EA, Kirsch AJ. Metabolic risk factors for stone formation in patients with cystic fibrosis. The Journal of urology. 2002;167(2):480-4.

21. Hassanzad M, Ansari M, Valinejadi A, Sayedi SJ, Velayati AA. Cystic fibrosis patients evaluation in the last decades in a referral center, Tehran-Iran. J International Journal of Pediatrics. 2019;7(8):9997-10007.

22. Ghergherechi R, Rafeey M, Habibzadeh A, Zamani M, Ansarin K, Shabestari MS. Recombinant human growth hormone effects on growth in cystic fibrosis. Ilam univesity of medical sciences journal. 2017;39(4):71-7.

23. Rafiei M, Pour Abdollahi P, Ghaem Maghami SJ, Samsami M, Por Hosein D, Nasiri A. Growth and Nutrition Pattern of Children with Cystic Fibrosis and Comparison with Healthy Children in West Azarbaijan Province, Iran. Urmia Medical Journal. 2010;20(4):278-83.

24. Haghi Ashtiani M, Rabiei N, Farahmand F, Mahbob F, Najafi M. Comparison of fecal elastase 1 and fecal trypsin diagnostic tests in CF patients with controls. Urmia Medical Journal. 2009;19(1):47-54.
25. Keiser NW, Engelhardt JF. New animal models of cystic fibrosis: what are they teaching us? Current opinion in pulmonary medicine. 2011;17(6):478.

26. Balestra AP, Bianchetti MG, Casaulta CA, Mullis PE, Lippuner K, Jaeger P. Which factors account for renal stone formation in cystic fibrosis? Clinical nephrology. 2003;59(3):160-3.

27. Gelfond D, Borowitz D, Hepatology. Gastrointestinal complications of cystic fibrosis. Clinical Gastroenterology. 2013;11(4):333-42.

28. Hoppe B, von Unruh GE, Blank G, Rietschel E, Sidhu H, Laube N, et al Absorptive hyperoxaluria leads to an increased risk for urolithiasis or nephrocalcinosis in cystic fibrosis. American journal of kidney diseases. 2005;46(3):440-5.

29. Hatch M, Cornelius J, Allison M, Sidhu H, PeckA, Freel RW. Oxalobacter sp. reduces urinary oxalate excretion by promoting enteric oxalate secretion. Kidney international. 2006;69(4):691-8.

30. Kaufman DW, Kelly JP, Curhan GC, Anderson TE, Dretler SP, Preminger $\mathrm{GM}$, et al. Oxalobacter formigenes may reduce the risk of calcium oxalate kidney stones. Journal of the American Society of Nephrology. 2008;19(6):1197-203.

31. Downes KJ, Goldstein SL. Biomarkers for Kidney Injury in Cystic Fibrosis. Biomarkers in Kidney Disease. 2016:689-718. 